\title{
Are medical associations relevant to young doctors?
}

\author{
— Cite as: CMAJ 2018 January 8;190:E23-4. doi: 10.1503/cmaj.109-5537
}

Posted on cmajnews.com on Dec. 12, 2017.

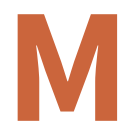

ajor medical associations are working hard to attract young doctors, but newer physicians tend to feel less represented by large associations than more senior colleagues.

One reason may be the increase in choices of specialist organizations, professional networks and advocacy groups for physicians over the past few decades, according to Dean West, president of the Association Laboratory, a Chicago-based consulting firm for professional associations.

Those who join associations, however, do so for similar reasons as previous generations. "They want someone to represent their interests, and they want to know they're being heard," said West.

One way the Canadian Medical Association (CMA) is engaging younger doctors is through its ambassador program, launched four years ago to bring medical students, residents and new-to-practice physicians to its annual meeting and general council.

"They don't just invite you, they take a lot of effort to include you in the conversations and get you to mix with the more established members," said Dr. Seema Marwaha, an internal medicine physician in Ontario who attended the CMA meeting under the program this year. She was impressed with the strong position the CMA took in favour of harm reduction, and appreciated that young doctors who disagreed with the majority of CMA members on federal taxation proposals were given a prominent platform to express their views.

Part of the impetus behind the ambassador program was to address the "drop off" the CMA sees among doctors in later residency and early-practice years, said Tim Smith, the association's CEO.

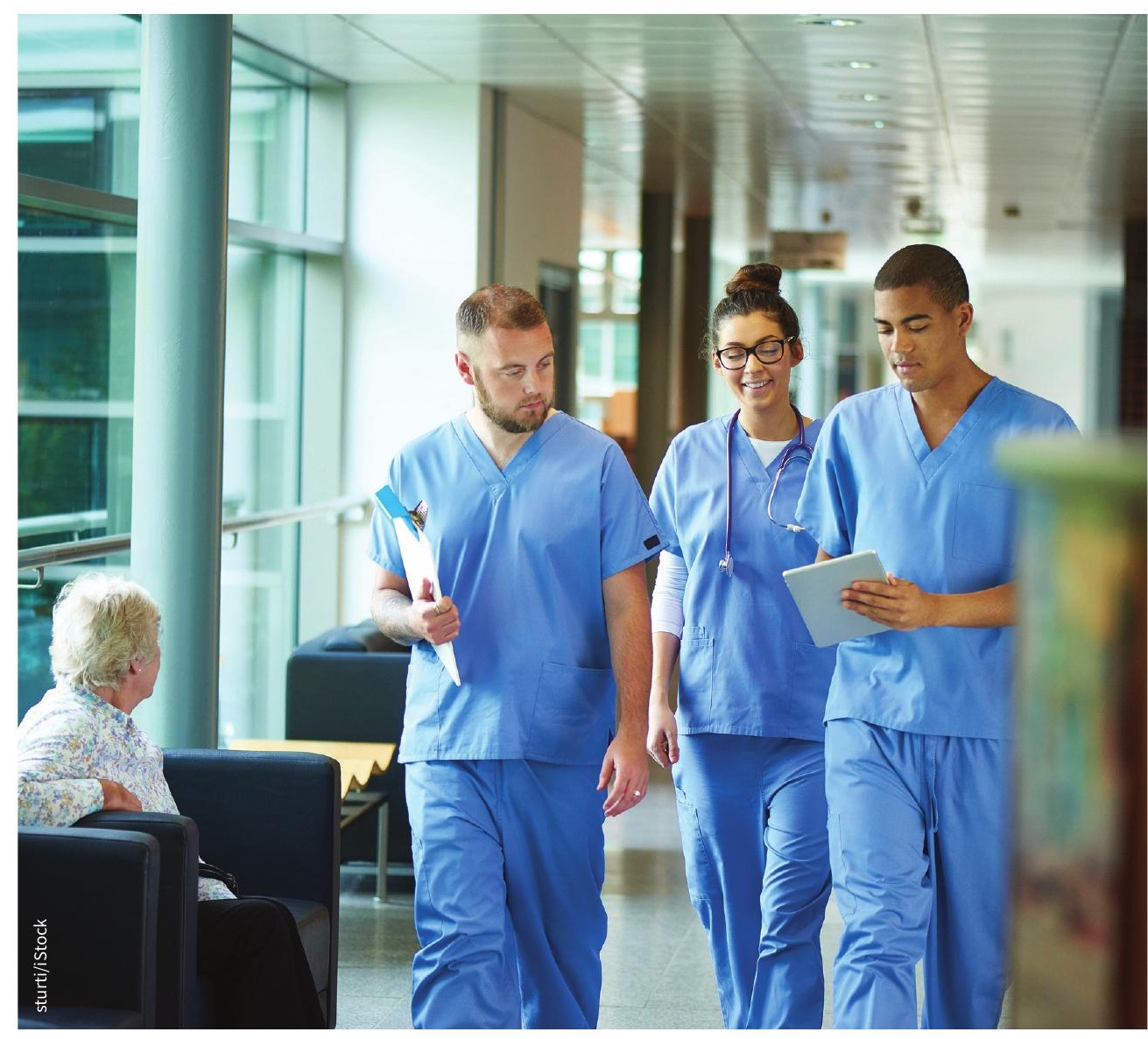

Many younger doctors would like to see greater diversity among the leaders and delegates of national medical associations.

Because students already belong to university-based organizations and the Canadian Federation of Medical Students, it's easy to reach students, said Smith. About $90 \%$ of medical students are members. But once they're out on their own, young physicians are busy and difficult to organize, he said.

Another problem, some newer to the profession have noted, is that many young doctors don't see themselves reflected in medical association leader- ship. "At the meeting, among the students and residents, the gender breakdown was about 50-50, and there were about 50\% visible minorities," said Marwaha. "But when you look at the established membership, it seemed like a bit of an old boy's club."

This divide was especially evident at the CMA awards ceremony, where all but two of the awards not intended for residents, students or early-career physicians went to white males. Some younger doc- 
tors voiced concern over the lack of diversity, and the CMA is working to seek out nominations more actively, especially from younger doctors, said Smith.

The American Medical Association faces similar challenges. Although $49 \%$ of members are under age 40 , only $14 \%$ of delegates are that young, according to 2017 statistics. But the numbers have been growing. In 2015, $46 \%$ of members and $12 \%$ of delegates were under 40 .

Dr. James Madara, CEO and executive vice-president of the American Medical Association, credits the membership increase among young doctors in part to the association's advocacy to preserve insurance for 20 million Americans covered by Obamacare. "We stake out ground much more forcefully in what we are for," he said.

Similarly, in Australia, "the advocacy of the organization is the primary reason why young doctors join," said Anne Trimmer, secretary general of the Australian Medical Association. The association took a strong stance this year on marriage equality legislation and recently called for more government attention to climate change's health effects.

Other topics that tend to attract young doctors include physician wellness and work-life balance, in addition to social justice, which is "huge for a lot of trainees," said Henry Annan, who sits on the CMA board as the president of the Canadian Federation of Medical Students

Some advocacy decisions made by medical associations, however, have been unpopular among young doctors. Last year, for example, the American Medical Association supported the nomination of Dr. Tom Price, a harsh critic of Medicaid and Obamacare, for Secretary of Health and Human Services. Three young physi- cians penned an open letter condemning the decision and more than 6000 other doctors signed it.

Another challenge, for all professional organizations, is keeping up with technology - an important factor for young people. In one survey of professionals under 40, $74 \%$ said professional associations are useful, but only $45 \%$ agreed they were tech savvy. Recognizing the importance of technology to continued relevance, the American Medical Association has made a push into technology-driven services, including an innovation network to connect physicians with entrepreneurs who have similar interests. In Canada, the CMA is set to launch a virtual community where young doctors can access peer support and mentorship, and get confidential advice if they're experiencing intimidation.

Wendy Glauser, Toronto, Ont. 